\title{
CHEMICAL AND BIOMETRICAL PROPERTIES OF PLUM WOOD AND ITS APPLICATION IN PULPAND PAPER PRODUCTION
}

\author{
Majid Kiaei $^{1, \AA}$, Milad Tajik ${ }^{2}$, Ramin Vaysi $^{1}$
}

\begin{abstract}
Plum (Prunus domestica) is one of the most widespread species of fruit trees in Asia and South-East Europe. There are large quantities of fruit wood trees without suitable usage in world. The aim of this research was to examine biometrical and chemical properties of the plum wood and its application in the pulp and paper industry. Five normal plum trees were randomly selected from Shahriyar province, Iran. A log cut down at stem (breast height) and branch for each of trees. The pith parts of cross-section were removed to examine the chemical (according to the TAPPI standard) and biometrical properties (according to the Franklin method). Results indicated that there were significant differences between stem and branch samples in fiber diameter and lumen diameter. Types of wood (branch and stem) had not significant differences on the chemical properties and fiber length, cell wall thickness and morphological properties. Among all of studied properties, the lignin, cellulose, fiber diameter, fiber lumen diameter, cell wall thickness and flexibility coefficient in branch wood is higher than stem wood. Although Runkel and flexibility coefficients of stem and branch fibers are lower than the accepted standard, but because of closing amount of lignin, extractive composition and fiber length to hardwood species, it can solve some of the problems of the lack of raw materials for paper production.
\end{abstract}

Keywords: Prunus domestica, stem, branch, biometrical properties, chemical properties.

\section{INTRODUCTION}

There are 12.7 million hectares agriculture lands in Iran, which over 2.6 million hectares of them are under the plantation of fruit trees. Every year 35 million seedlings of fruit trees produce and disperse at different region. Among these fruit trees, Prunus domestica is one of the most important fruit trees in 38547 hectares under cultivation in Iran. Iran has the fifth degree of producing of plum fruit production in world. According to the peak fruiting trees and short life of plum trees (8-10 years-old) needs to be cut and replaced by new trees after these years. Therefore, large quantities of wood residues are destroyed without suitable usage.

Anatomical characteristics form the basis for wood utilization in pulp and paper making industry. The properties of paper depend on the fiber properties, anatomy and method of separation of the fibers. Fiber characteristics that influence the quality of paper are: length, fiber diameter, fiber lumen width, fiber cell wall thickness, Runkel ratio, Co-efficient flexibility and the relative fiber length (Zobel and Van Buijtenen 1989). The fiber length is the number of bonding sites that is available on an individual fiber to form an interwoven network of fibers. It is measured from one end to another end. Long fiber lengths are preferable for manufacture of paper. Long fibers give a more open and less uniform sheet structure. Fiber length influences the tearing strength of paper. The higher of the fiber length had effect on the resistance of the paper to tearing (Oluwadare and Ashimiyu 2007, Bhat et al. 1989, Wimmer et al. 2002). Fiber diameter is the diameter of fibre measured from side to side end and it is usually

\footnotetext{
${ }^{1}$ Department of Wood and Paper Engineering, Chaloos Branch, Islamic Azad University, Chaloos, Iran

${ }^{2}$ Young Researchers and Elite club, Chaloos Branch, Islamic Azad University, Chaloos, Iran and M. Sc student Shahid Beheshti University, Iran

^Corresponding author: Mjd_kia59@yahoo.com

Received: 17.03.2013 Accepted: 18.10.2013
} 
measured across the fiber length. The fibre lumen width is the diameter of the internal cavity. It is the distance between the inside diameter and the outer cavity. It is measured in a transverse direction. Faber lumen width affects the beating of pulp. The larger the fiber lumen width, the better will be the beating of pulp because of the penetration of liquids into empty spaces of the fibers. Fiber cell wall thickness is the thickness of the cell wall which is determined by the age of the tree. Its proportion varies in trees. It was reported that matured wood are thick walled while juvenile wood fibers are thin walled (Clark 1962, Clark and Saucier 1989). Thick wall fibers adversely affect the bursting strength, tensile strength and folding endurance of paper. The paper manufactured from thick walled fibers will be bulky, coarse surface and contain a large amount of void volume. So, paper with thin walled fiber will be dense and well formed.

The Runkel ratio is the ratio of fiber cell wall thickness to its lumen that determines the suitability of a fibrous material for pulp and paper production. If a wood species has a high Runkel ratio, its fiber will be stiff and less flexible and poor bonding ability. High Runkel ratio fibers produce bulkier paper than fibers with low Runkel ratio. For any wood species to be of good quality for pulp and paper production, its Runkel ratio must be 1 (Xu et al. 2006, Enayati et al. 2006). The coefficient of flexibility, usually expressed in percentage, is derived from the ratio of lumen width to its fiber diameter. Coefficient of flexibility gives the bonding strength of individual fiber and by extension the tensile strength and bursting properties (Wangaard 1962). Relative fiber length is the ratio of the fiber length to its diameter; it gives the tearing resistance of a paper (Varghese et al. 1995).

There are two major chemical components in wood: lignin (18-35\%) and carbohydrate $(65-75 \%)$. Both are complex, polymeric materials. minor amount of extraneous materials, mostly in the form of organic extractives and inorganic minerals (ash), are also present in wood (usually 4-10\%). overall. wood has an elemental composition of about $50 \%$ carbon, $6 \%$ hydrogen, $44 \%$ oxygen, and trace amount of several metal ions (Zobel and van Buijtenen 1989, Panshin and de Zeeuw 1980).

Wood fiber characteristics and chemical composition are two important parameters which determine its suitability as raw material for the production of pulp and paper. The extractive content has a direct effect on the pulp yield, a high content reduce pulp yield. On other hand holocellulose, $\alpha$-cellulose and lignin content are mainly related to pulping behavior, whereas morphology of fiber affects paper strength (Zobel and van Buijtenen 1989, Panshin and De zeeuw 1980).

Jahan et al. (2010) on the anatomical, morphological and papermaking properties of Trema orientalis wood in three different sites in Bangladesh reported that a significant difference between branch and stem were observed. Stem wood had more $\alpha$-cellulose, less lignin and longer fibers than branch wood for three studied sites. Abdul-khalil et al. (2006) on the chemical composition of oil palm frond, coconut, pineapple leaf and banana stem reported that banana stem fibers exhibited the highest solubility in ethanol-benzene $(10,6 \%)$, compared to other fibers. The highest and lowest values of lignin content were found in coconut and pineapple leaf, respectively.

The increased demand for wood and fiber and declining availability of wood supplies have prompted investigations the potential of fruit trees residues as raw material for the pulp and paper industry. Hence it is need to exactly investigation on the new raw material for pulp and paper production. In this paper, we determined the chemical, biometrical properties and morphological indexes of the stem and branch samples in plum wood (Prunus domestica) and its relationship in pulp and paper production. 


\section{MATERIAL AND METHODS}

\section{Wood samples}

The Prunus domestica L. samples (7-10 years-old) were collected from the Shahriyar province in Iran. Five normal trees were randomly selected to determine chemical and biometry properties. Discs (stem and branch) were cut down from each tree. Diameter of stem and branch wood are $18 \mathrm{~cm}$ and 10 $\mathrm{cm}$, respectively. The stem samples (5 discs) were prepared at breast height, while the branch samples (five discs) were prepared $1 \mathrm{~cm}$ above from the connecting between branch and stem. These trees have low age and low diameter, which have juvenile wood. For testing samples, pith part was removed to examine chemical and physical properties (Figure 1).

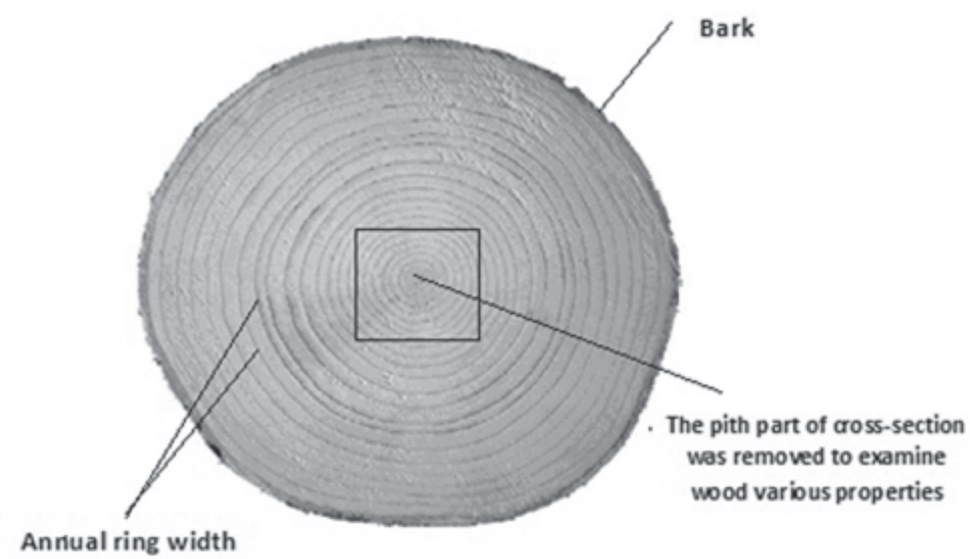

Figure 1. Samples pattern along cross-section to measure wood chemical and biometrical properties.

\section{Biometrical properties}

50 samples were taken from stem and branch wood for investigation fiber dimension such as fiber length, fiber diameter, lumen diameter and cell wall thickness. Franklin (Franklin 1945) method was used for separation of wood fibers. Specimens for measuring fiber dimensions were macerated in a mixture (1:1) of $30 \%$ hydrogen peroxide and glacial acid in a $64^{\circ} \mathrm{C}$ oven for 24 hours. After maceration, the samples were washed with distilled water. The fiber dimensions were determined by Leica Image Analysis System. For this test, it was necessary to measure 20 fiber dimensions per sub-samples. The calculations of Runkel ratio $(2 *$ cell wall thickness/lumen diameter $\times 100)$, coefficient of flexibility (lumen diameter/fiber length $\times 100$ ), and slenderness (fiber length/fiber diameter) were carried out using the measured data.

\section{Chemical composition}

The chemical compositions were carried out following TAPPI Test Methods (T $257 \mathrm{~cm}-85$ ): the lignin (T $222 \mathrm{om}-98)$, ash (T $211 \mathrm{om}-93$ ), solubility in hot water (T $207 \mathrm{~cm}-88)$ and alcohol-acetone (T $204 \mathrm{~cm}-88)$. The cellulose content of plum wood was determined according to the nitric acid method (Rowell et al. 1997). All measurements were repeated three times. We have five disc samples from stem $(5$ trees $\times 3$ times $=15)$ and five disc samples from branch wood $(5$ trees $\times 3$ times $=15)$. 
Finally, T-test was used to determine significant difference between stem and branch plum wood samples in chemical and biometry properties. These results of wood various properties of pulm wood were compared with other fruit tress wood such as Kiwi (Actinidia Spp), Prunus armeniaca, coconut (Cocos nucifera L.) and banana stems (due to be belong to the garden production) in Iran and world.

\section{RESULTS AND DISCUSSION}

\section{Lignin content}

Figure 2 shows the mean and standard deviation in branch and stem of pulm wood. There is no significant difference between stem and branch samples in the lignin content. The lignin content in branch sample was slightly higher than stem sample. This result was previously reported by Jahan et al. (2010) for Trema orientalis wood.

Lignin is an undesirable polymer, and its removal during pulping requires high amounts of energy and chemicals. The average of lignin content in plum wood was $32,26 \%$ for stem sample and $33,62 \%$ for branch sample, which is higher than banana stem (18,6\%, Abdul-khalil et al. 2006). Although pulm fibers contained the highest percentage of lignin, but the lignin value of pulm wood was still lower than that of softwood (21-37\%, Tsoumis 1996) and hardwood species (14-34\%; Tsoumis 1996). The mean of lignin content in pulm stem wood and branch wood were similar than that from coconut fibers $(32,8 \%$; Abdul-khalil et al. 2006) and Prunus armeniaca wood (31\%; Tajik 2012).

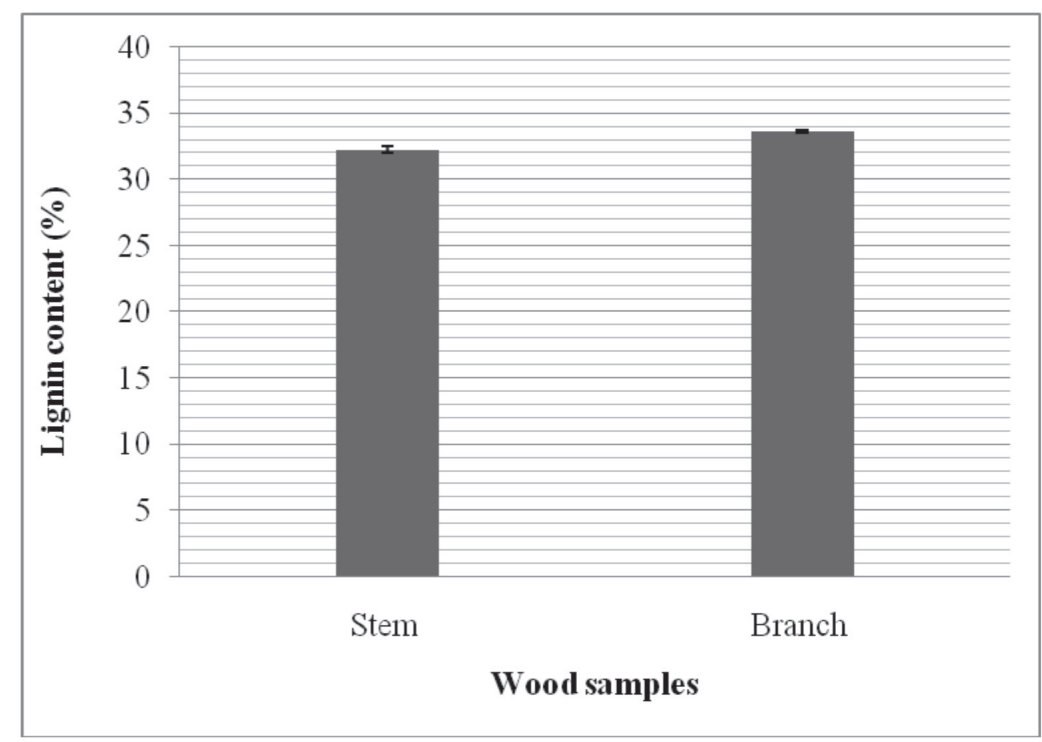

Figure 2. The value of lignin content in plum wood. 


\section{Cellulose content}

The average of cellulose content in branch sample was slightly higher than stem sample. There is not a significant difference between branch and stem samples in the cellulose content. The cellulose values of plum wood are 51,66 and 53,24\% for stem and branch samples, respectively (Figure 3). It is satisfactory for pulp and paper production (close to or above 40\%; Abdul-khalil et al. 2006). This characteristic was observed in stem and branch of plum wood. Generally, there are positive relationship between pulp quality and cellulose content.

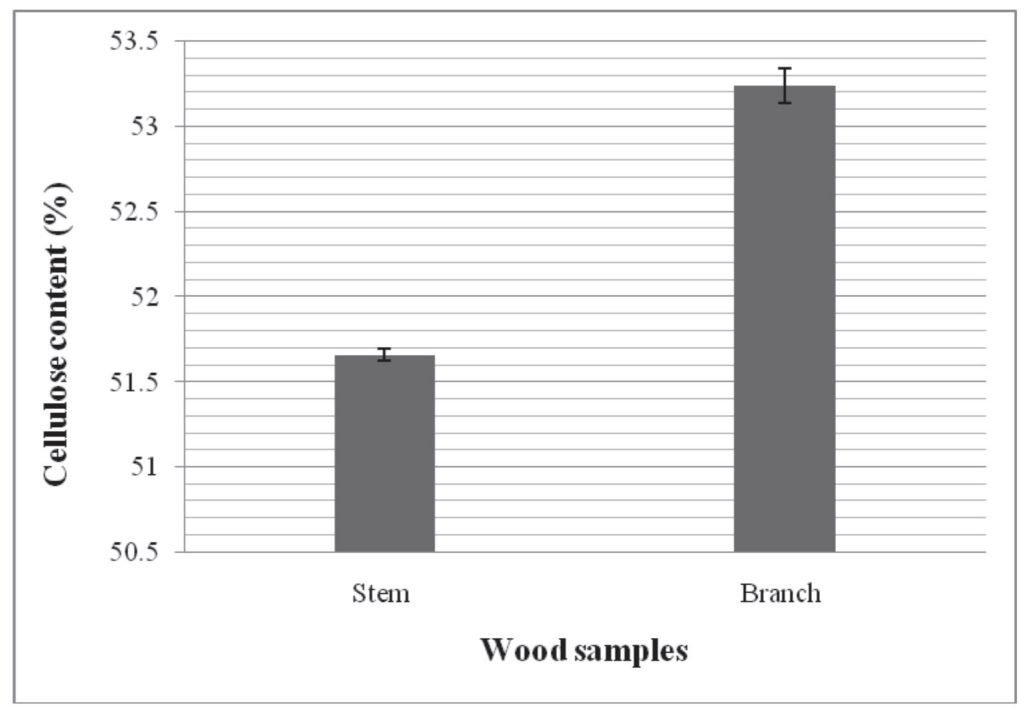

Figure 3. The value of cellulose content in plum wood.

\section{Extractive content}

Wood extractive cause many problems in pulp and paper processes and decrease the quality of the final product. Extractives of a raw material are undesirable parts since they can have negative impact on the pulping and bleaching operations. For example, a higher extractive content may lead to a lower pulp yield from the kraft and soda processes (Jahan et al. 2008b and 2010). The extractives contents, including those from hot water and alcohol-acetone are higher in the stem samples than the branch wood. The mean of extractive content from hot water and alcohol-acetone were 4,17 and 2,85\% for stem samples, respectively. The corresponding values for branch samples were 3,44 and 1,53\% (Figure 4). There are no significant differences between stem and branch samples in the both extractive content. The hot water extractive content in plum wood were similar than that from hardwood $(0,1-7,7 \%$, Tsoumis 1996) and softwood species (0,2-8,5\%, Tsoumis 1996). The amount of extractives is lower than that of coconut fibers (6,4\%, Abdul-khalil et al. 2006) and banana stems (10,5\%, Abdul-khalil et al. 2006). 


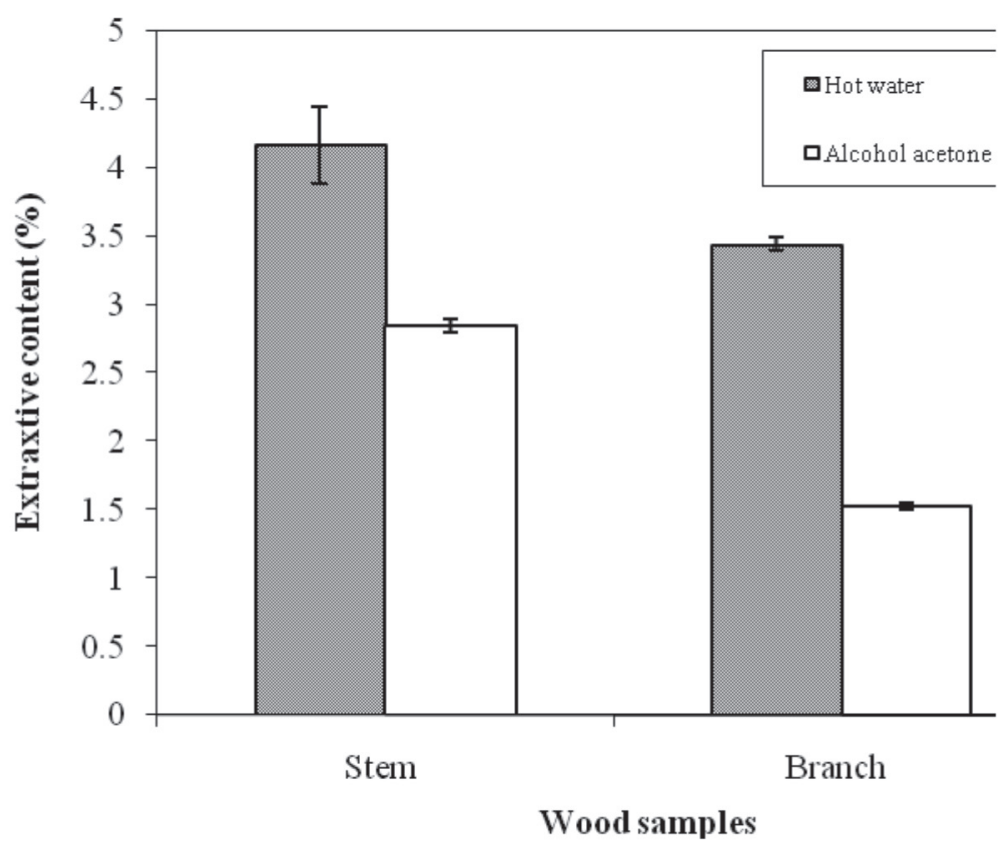

Figure 4. The value of extractive content in plum wood.

\section{Fiber dimension}

The descriptive statistics of fiber length, fiber diameter, cell wall thickness and lumen diameter are shown in table 1. There are significant differences between stem and branch samples in fiber diameter and lumen diameter. Wood samples had not significant difference on the fiber length and cell wall thickness. The fiber diameter and fiber lumen diameter in branch sample are higher than stem sample.

The fiber length of stem and branch wood are 0,978 and $0,968 \mathrm{~mm}$, respectively. These values are shorter than softwood (2,7-4,6 mm, Tsoumis 1996), Kiwi residues (1,371 mm, Vaysi and Yosefi 2008), and are the range of hardwood fibers $(0,7-1,6 \mathrm{~mm}$, Tsoumis 1996). The value of fiber diameter is 13,77 $\mu \mathrm{m}$ for stem sample and is $16,83 \mu \mathrm{m}$ for branch wood. The value of lumen diameter for stem and branch samples were determined 5,60 and 7,99 $\mu \mathrm{m}$, respectively. Also, the amount of cell wall thickness in stem wood $(4,08 \mu \mathrm{m})$ is higher than branch wood $(4,42 \mu \mathrm{m})$. The fiber diameter, lumen diameter and cell wall thickness in plumwood is smaller than that of Kiwi wood (Table 1).

Fibers were classified into three groups. The first group was considered short fibers with lengths of less $0,90 \mathrm{~mm}$ such as hardwood. The second group, like plum wood, had an average length between 0,9-1,9 $\mathrm{mm}$. the results showed that the average fiber length of plum wood was 0,978 for stem sample and 0,968 for branch sample. The third group included fibers loner than 1,9 $\mathrm{mm}$ (Salehi 2001). Overall, there are positive relationships between fiber length and burst strength (Casey 1952, Miyake 1968, ElHosseiny and Anderson 1999, Ona et al. 2001), tensile strength (Casey 1952, Miyake 1968), tear strength (Casey 1952, Haygreen and Bowyer 1996) and folding endurance (Dinwoodie 1965, Ona et al. 2001). 
Table 1. The descriptive statistics of fiber dimension in plumwood and Kiwi (Actinidia Spp) wood.

\begin{tabular}{|c|c|c|c|c|c|}
\hline \multicolumn{2}{|c|}{ Samples } & FL & FD & LD & CWT \\
\hline \multirow[t]{4}{*}{ Stem } & Mean & 978,51 & 13,77 & 5,60 & 4,08 \\
\hline & SD & 107,8 & 2,29 & 1,36 & 1,12 \\
\hline & Min & 776,24 & 8,72 & 3,27 & 1,47 \\
\hline & Max & 1240,55 & 17,95 & 9,56 & 6,08 \\
\hline \multirow[t]{4}{*}{ Branch } & Mean & 968,24 & 16,83 & 7,99 & 4,42 \\
\hline & SD & 83,62 & 2,56 & 1,84 & 1,55 \\
\hline & Min & 799,45 & 11,32 & 4,75 & 0,82 \\
\hline & Max & 1151,91 & 21,98 & 12,14 & 7,38 \\
\hline Kiwi wood* & Mean & 1371 & 30,04 & 14,17 & 7,93 \\
\hline
\end{tabular}

FL: Fiber length $(\mu \mathrm{m}), \mathrm{FD}$ : Fiber diameter $(\mu \mathrm{m}), \mathrm{LD}$ : lumen diameter $(\mu \mathrm{m})$, CWT: cell wall thickness $(\mu \mathrm{m})$

*Vaysi and Yosefi (2008).

The descriptive statistics for morphological properties are shown in table 2 . There are not significant different between branch and stem wood in the flexibility, Runkel and slenderness coefficients. Overall, the amount of flexibility coefficient in branch wood is higher than stem wood, while the values of Runkel and slenderness ratio in the branch wood are low. The slenderness and Runkel ratio of plum wood is higher than Kiwi wood, whereas the flexibility coefficient of Kiwi wood is higher than plum stem wood and is lower plum branch sample (Table 2).

Flexibility coefficient is the percentage of lumen width over fiber width. It expresses the potential of fiber to collapse during beating, or during drying of the paper web. Collapsed fibers provide more bonding area and subsequently stronger papers are produced. On the other hand, strength properties of paper such as tensile strength, bursting strength and folding endurance are affected mainly by the way in which individual fibers are bonded together in paper sheets. The degree of fiber bonding depends largely on the flexibility of individual fibers (Zobel and van Buijtenen 1989). There are four groups according to the flexibility ratio (Bektas et al. 1999): 1- high elastic fiber (having flexibility ratio greater than 75), 2- elastic fiber (flexibility coefficient between 50-75), 3- rigid fiber (flexibility ratio between 30-50), and 4- high rigid fibers (flexibility coefficient less than 30). As a result observed fibers of plum wood classify in rigid fibers group. The rigid fibers do not have efficient elasticity and they aren't suitable for paper production.

In general, there is a positive relationship between slenderness ratio and folding endurance (Dinwoodie 1965, Ona et al. 2001), and between flexibility coefficient and burst (Ona et al. 2001), and breaking length and tear resistance (Mabilangan and Estudillo 1996). Standard values of Runkel ratio are less than 1 . Regarding to this, the plum stem sample $(1,56)$ and branch wood $(1,21)$ aren't suitable for pulp and paper production.

Accepted values of slenderness coefficients are more than 33. According to this morphological property, the stem wood $(73,38)$ and branch sample $(58,85)$ of plum wood are suitable for paper production, although they would be classified as average fibers. 
Table 2. The descriptive statistics of fiber morphological properties in plum (Prunus domestica) wood.

\begin{tabular}{ccccc}
\hline \multirow{2}{*}{ Samples } & & FC & SC & RC \\
\hline \multirow{2}{*}{ Stem } & Mean & $\mathbf{4 1 , 3 8}$ & $\mathbf{7 3 , 2 8}$ & $\mathbf{1 , 5 6}$ \\
& SD & 10,40 & 16,58 & 0,651 \\
\hline \multirow{2}{*}{ Branch } & Mean & $\mathbf{4 8 , 5 8}$ & $\mathbf{5 8 , 8 5}$ & $\mathbf{1 , 2 1}$ \\
& SD & 13,50 & 10,54 & 0,59 \\
\hline Kiwi wood * & Mean & 46,80 & 45,89 & 1,16 \\
\hline
\end{tabular}

FC: flexibility coefficient, SC: slenderness coefficient, RC: runkel coefficient, SD: Standar deviation

*Vaysi and Yosefi (2008).

\section{CONCLUSIONS}

Significant differences in wood fiber diameter and lumen diameter existed between the stem and branch samples in Prunus domestica.

Branch wood samples had highest values of lignin, cellulose, fiber diameter, fiber lumen diameter, cell wall thickness and flexibility coefficient in

Plum wood fibers are the most suitable for pulp and paper production, due to adequate chemical properties, fiber length and slenderness coefficients. Although Runkel and flexibility coefficients are lower than the accepted standard, but plum wood can solve some of the problems of the lack of raw materials for paper production due to the same properties as hardwood species. 


\section{REFERENCES}

Abdul-khalil, H.P.S.; Siti Alwani, M.; Mohd Omar, A. K. 2006. Chemical composition, anatomy, lignin distribution, and cell wall structure of Malaysian plant waste fibers. Bioresource 1 (2): 220-232.

Bektas, I.; Tutus, A.; Eroglu, H. 1999. A study of the suitability of Calabrian pine (Pinus brutia Ten.) for pulp and paper manufacture. Turkish journal of Agriculture and Forestry 23: 589-599.

Bhat, K. M.; Bhat, K.V.; Dhamodaran, T. K. 1989. Fiber length variation in stem and branches of eleven tropical hard woods. IAWA Journal 10 (1): 63-70.

Casey, J.P. 1952. Properties of paper and converting. In Pulp and Paper Chemistry and Chemical Technology. Volume 2. Interscience Publisher Inc., New York.

Clark, J. 1962. Effects of fiber coarseness and length, I. Bulk, burst, tears, fold and Tensile tests. Tappi Journal 45: 628-634.

Clark, A.; Saucier, J.R. 1989. Influence of initial planting density, geographic location and species on juvenile wood formation in southern pine. Forest Prod Journal 39: 42-48.

Dinwoodie, J. M. 1965. The relationship between fiber morphology and paper properties: a review of literature. Tappi Journal 48: 440-447.

El-Hosseiny, F.; Anderson, D. 1999. Effect of fibre length and coarseness on the burst strength of paper. Tappi Journal 82: 202-203.

Enayati, A. A.; Hamzeh, Y.; Mirshokraie, S. A.; Molaii, M. 2009. Papermaking potential of canola stalks. Bioresource 4 (1): 245-256.

Franklin, G. L. 1945. Preparation of thin sections of synthetic resins and wood-resin composites, and a new macerating method for wood. Nature 155(3924):51-59.

Haygreen, J.G.; Bowyer, J.L. 1996. Forest Products and Wood Science: An Introduction. Third edition. Iowa University Press, Ames.

Jahan; M.S.; Chowdhury, N.; Ni, Y. 2010. Effect of different locations on the morphological, chemical, Pulping and papermaking properties of Trema orientalis (Nalita). Bioresource Technology 10: 1892-1898.

Jahan, M.S.; Ahsan, L.; Noori, A.; Quaiyyum, M.A. 2008b. Process for the production of dissolving pulp from Trema orientalis (Nalita) by prehydrolysis kraft and soda-ethylenediamine (EDA) process. BioResearch 3(3): 816-828.

Mabilangan, L. C.; Estudillo, C.P. 1996. Philippines woods suitable for kraft pulping process. Trade Bulletin Series 5: 1-9.

Miyake, M. 1968. Wood characteristics and Kraft pulp properties of hardwood grown in Hokkaido. Japan Tappi 22: 600-610. 
Oluwadare, A.O.; Ashimiya, O.S. 2007. The relationship between fiber characteristics and pulpsheet properties of Leucaena leucocephala (Lam) De Wit. Middle East Journal of Scientific Research 2(2): 63-68.

Ona, T.; Sonoda, T.; Ito, K.; Shibata, M.; Tamai, Y.; Kojima, Y.; Ohshima, J.; Yokota, S.; Yoshizawa, N. 2001. Investigation of relationship between cell and pulp properties in Eucalyptus by examination of within-tree property variations. Wood Science and Technology 35: 363-375.

Panshin, A.; De zeeuw, C. 1980. Text book of wood technology. $4^{\text {th }}$ edition, McGraw-Hill, New York.

Rowell, R. M.; Young, R.A.; Rowell, J. K. 1997. Paper and composites from Agro-based resource, CRC Lewis publisher, Boca Raton, FL, USA.

Tajik, M. 2012. The chemical and biometrical properties of Prunus armeniaca wood in Tehran region. M. A. dissertation. Chaloos Branch, Islamic Azad University (IAU), Iran. 68p.

TAPPI (Technical Association of the Pulp and Paper Industry). 1994. Tappi Test Methods 1994. Tappi press, Atlanta.

Tsoumis, G. 1996. Science and technology of wood: structure. properties and utilization, Van Nostrand Reinhold, New york. USA.

Salehi, K. 2001. Study and determine the properties of chemi-mechanical pulping high yields from bagasse. Wood and paper Research No. 232, Research Institute of Forests and Rangelands.

Vaysi, R.; Yosefi, F. 2008. An investigation on the production possibility of NSSC pulp and fluting papers from Kiwi residues. Journal of Sciences and Techniques in Natural Resources 3(1): 51-64.

Varghese, M.; Vishnu, K.N.S.; Bennt, S.S.R.; Jaghdes, S. 1995. Genetic effect on wood and fiber traits of Ecalyptus grandis provenances. In Eucalypt Plantations: Improving fibre Yeild and Quality. CRCTHF-IUFRO Conference: Hobart, Australia 19-24 february 1995. pp. 64-67.

Wangaard, F.F. 1962. Contributions of hardwood fibres to the properties of kraft pulps. Tappi Journal 45: 548-556.

Wimmer, R.; Downes, G.M.; Evans, R.; Rasmussen, G.; French, J. 2002. Direct Effects of Wood Characteristics on Pulp and Handsheet Properties of Eucalyptus globulus. Holzforschung 56: 244-252.

Xu, F.; Zhong, X.C.; Sun, R.C.; Lu, Q. 2006. Anatomy, ultra structure, and lignin distribution in cell wall of Caragana korshinskii. Industrial Crops and Production 24: 186-193.

Zobel, B. J.; van Buijtenen, J.P. 1989. Wood Variation: Its Causes and Control. Springer-Verlag, Berlin, Heidelberg, New York. 